\title{
Effect of cutting parameters on tool-chip interface temperature in an orthogonal turning process
}

\begin{abstract}
The aim of this paper is to investigate the effect of cutting speed and uncut chip thickness on cutting performance. A Finite Element Method (FEM) based on the ABAQUS explicit software which involves Johnson-Cook material mode and Coulombs friction law was used to simulate of High Speed Machining (HSM) of AISI 1045 steel. In this simulation work, feed rate ranging from $0.05 \mathrm{~mm} / \mathrm{rev}$ to $0.13 \mathrm{~mm} / \mathrm{rev}$ and cutting speed ranging from 200 $\mathrm{m} / \mathrm{min}$ to $600 \mathrm{~m} / \mathrm{min}$ at three different cutting speeds were investigated. From the simulation results it was observed that increasing feed rate and cutting speed lead to increase temperature and stress distribution at tool/chip interface. The results obtained from this study are highly essential to predict machining induced residual stresses and thermo-mechanical deformation related properties on the machined surface.
\end{abstract}

Keyword: Cutting speed; Feed rate; Finite element modeling 